\title{
Unusual Skin tear caused by eye taping using acrylic-based adhesive tape in a adult patient with recurrent craniopharyngioma
}

\author{
Nirupa Ramakumar ${ }^{1}$, Sumedha Suresh
}

Skin tears due to medical adhesives are a ubiquitous but under documented complication that occurs in almost all clinical settings and frequently in patients with certain risk factors. Due to lack of information regarding proper usage, suitable selection and the right technique for application of adhesive products can influence patient safety besides hampering the quality of life. Medical adhesives-related skin injuries (MARSI) is the latest term used, defined 'an occurrence in which erythema and/or other manifestations of cutaneous abnormality (including, but not limited to, vesicle, bulla, erosion or tear) persists $30 \mathrm{~min}$ or more after removal of the adhesive' [1]. We describe a report of skin tear due to acrylic based adhesive in a young male who underwent craniotomy and tumor excision.

A 21 year-old-male with a diagnosis of a recurrent craniopharyngioma was posted for a Pterional craniotomy and excision of the tumour. The patient had secondary hypothyroidism and secondary hypocortisolism on thyroid and steroid replacement respectively. He was shifted to the OT and after attaching all the standard ASA monitors, he was induced after adequate preoxygenation, with Fentanyl, Propofol and Vecuronium and intubated with a $8.5 \mathrm{~mm}$ sized ET tube. A central venous catheter was inserted post induction in the right subclavian vein and was fixed with an adhesive tape. Before positioning the patient, scalp block with $15 \mathrm{ml}$ of $0.5 \%$ bupivacaine was administered. The eyelids were then taped with acrylic-based adhesive tape. The duration of the surgery was approximately 11 hours. In view of the prolonged nature of the surgery, the decision was made to not extubate the patient in the OT and to shift him to the Intensive Care Unit for further management and elective ventilation. Before the patient was shifted out of the OT, the adhesive tapes over his eyes were removed. While the left eye and periorbital region were found completely normal, the right periorbital region was mildly denuded after removal of the tape (Figure 1). The area around the central venous catheter where the same tape had been applied was normal.

Medical adhesive tapes are made of various materials, with each material offering its set of advantages and disadvantages. Injury to

the skin after use of adhesive tapes is a known, albeit a rare complication observed. Various risk factors for the development of skin injury include fragile skin, long duration of application, and chronic use of steroids etc., Retention of moisture underneath the tape before its application can also increase the chances of skin denudation. In our patient, it is possible that the area where the tape had been applied had been wet from the scalp block at the time of application. The moisture could have got retained for the duration of the surgery leading to the trauma. The acrylate tape is less moisture resistant than the silicone tapes so they must be used judiciously. The area to be covered by the tape must be moisturefree before the application.

Zeng et al in 2015 did a prospectively randomised controlled study in 60 patients comparing the $3 \mathrm{M}$ Kind Removal Silicone Tape versus standard acrylate based adhesive tapes (3M Durapore and Micropore tape) for facial skin injury and patient satisfaction in atrisk patients under general anesthesia [2]. They found silicontapes had less skin injury as compared to acrylic based tapes. Its essential to take into account the risk factors that can predispose the patient to skin tears and choose an appropriate tape therefore. The anaesthesiologist should be aware of MARSI as its occurrence though rare can significantly effect the patient care.

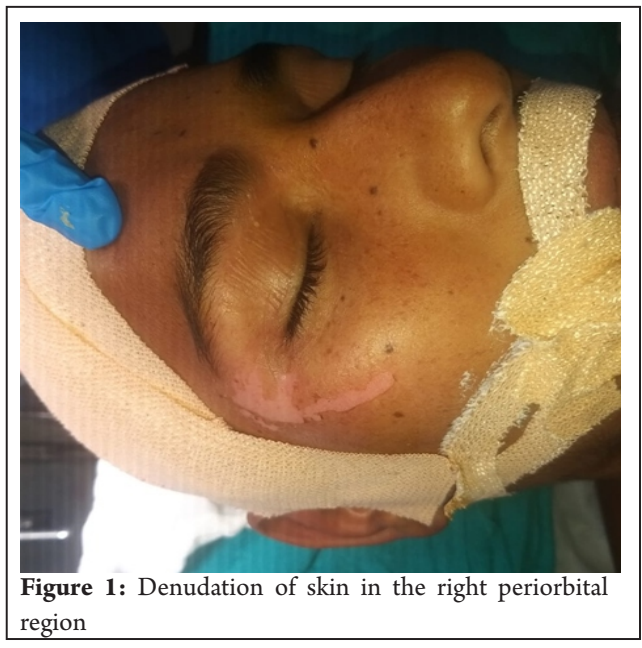

'Department of Anaesthesia, AIIMS Rishikesh, Uttarakhand, India.

Address of Correspondence

Dr. Nirupa Ramakumar

Department of Anaesthesia, AIIMS Rishikesh, Uttarakhand, India.

E-mail: niru27r@gmail.com

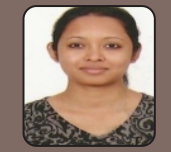

Dr. Nirupa Ramakumar

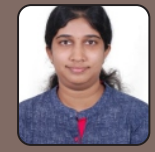

Dr. Sumedha Suresh

Submitted: 12 December 2020; Reviewed: 24 February 2021; Accepted: 7 April 2021; Published: 10 May 2021

$$
\text { DOI: 10.13107/jaccr.2021.v07i02.179 }
$$

This is an Open Access article distributed under the terms of the Creative Commons Attribution Non-Commercial-Share Alike 4.0 License (http://creativecommons.org/licenses/by-nc-sa/4.0) which allows others to remix, tweak, and build upon the work non-commercially as long as appropriate credit is given and the new creation are licensed under the identical terms. 
Declaration of patient consent: The authors certify that they have obtained all appropriate patient consent forms. In the form, the patient has given his consent for his images and other clinical information to be reported in the Journal. The patient understands that his name and initials will not be published, and due efforts will be made to conceal his identity, but anonymity cannot be guaranteed.

\section{Conflict of interest: Nil Source of support: None}

\section{References}

1. McNichol L, Lund C, Rosen T, Gray M. Medical adhesives and patient safety: state of the science: consensus statements for the assessment, prevention, and treatment of adhesive-related skin injuries. Orthop Nurs. 2013 Oct;32(5):267-81.
2. Zeng LA, Lie SA, Chong SY. Comparison of Medical Adhesive Tapes in Patients at Risk of Facial Skin Trauma under Anesthesia. Anesthesiol Res Pract 2016 [cited 2020 Dec 7];2016. Available from: https://www.ncbi.nlm.nih.gov/pmc/articles/PMC4921133/

\section{How to Cite this Article}

Ramakumar N, Sumedha S | Unusual Skin tear caused by eye taping using acrylic-based adhesive tape in a adult patient with recurrent craniopharyngioma | Journal of Anaesthesia and Critical Care Case Reports | May-August 2021; 7(2): 27-28. 